\title{
Peertechz
}

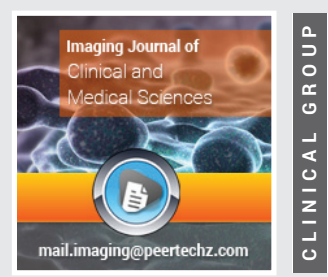

Clinical Image

\section{Exclusive Image Gallery on Human Spinal Cord Regeneration}

\section{Giselher Schalow*}

MD, PhD, Untere Kirchmatte 6, CH-6207 Nottwil, Switzerland

Received: 22 May, 2019

Accepted: 15 June, 2019

Published: 16 June, 2019

*Corresponding author: Giselher Schalow, Professor, Untere Kirchmatte 6, CH-6207 Nottwil, Switzerland, E-mail: g_schalow@hotmail.com

https://www.peertechz.com

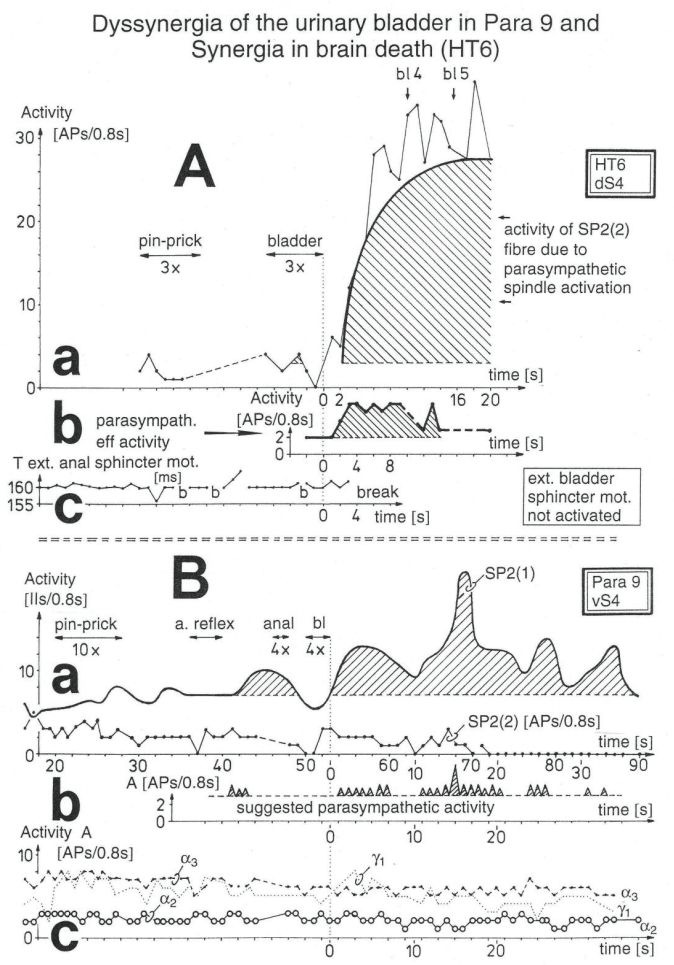

Figure 30: Direct comparison of secondary muscle spindle afferent activity and motoneuron activity between the brain-dead human HT6 with a synergy of the bladder (A) and the paraplegic 9 with a dyssynergia of the bladder (B)

A. Simultaneous measurements of activities of secondary muscle spindle afferents (a), parasympathetic preganglionic motoneurons (b) and oscillatory firing (high activity mode) of a sphincter motoneuron innervating the striated anal sphincter (c). Note that with the transient activity increase of the parasympathetic fibers (b) the secondary muscle spindle afferent fiber increased strongly its activity (a) for minutes, and the oscillatory firing sphincter motoneuron discontinued its oscillation (c) to reduce strongly its activity. bladder $3 x=3$ times bladder catheter pulling. T ext. anal sphincter mot. = oscillation period of the sphincter $\alpha_{2}-$ motoneuron innervating the anal sphincter. For further details, see Chapter V of [1].

Copyright: ( $) 2019$ Schalow G. This is an open-access article distributed under the terms of the Creative Commons Attribution License, which permits unrestricted use distribution, and reproduction in any medium, provided the original author and source are credited. 